\title{
Jogos de Improvisação Teatral na Formação do Artista-Professor-Pesquisador
}

Resumo: Nesta pesquisa, parto da premissa de que a formação do artistaprofessor-pesquisador acontece no ato da criação artística, tendo a sala de ensaio como espaço de jogo que agrega relações entre o fazer teatral, os sujeitos e o mundo. Integrando o eixo temático Formação de Professores de Teatro, tenho por objetivo compreender como os aspectos criativos, pedagógicos e científicos atuam nas experiências com jogos de improvisação em sala de ensaio. Para tanto, tomo como base teorias de jogos de improvisação consolidadas no âmbito do ensino do teatro: criação de cenas, fruição e recepção, apresentadas como sistemas adaptáveis à diferentes contextos de ensino/aprendizagem, propostas por Augusto Boal (2015) e Viola Spolin (2010); bem como o olhar pedagógico de Jean-Pierre Ryngaert (2009) sobre a variedade de indutores de jogo e aspectos favoráveis e desfavoráveis na improvisação. Através de registros de processos de criação teatral, os jogos estudados foram selecionados, transcritos e categorizados como jogos de iniciação, montagem e afinação de cenas. Atualmente, a pesquisa requer aplicação dos jogos em oficina de formação para compreender como os mesmos operam na formação do artista-professorpesquisador. Como conclusão parcial, compreendo que jogos estudados abarcam três aspectos: criação artística (pelo direcionamento à montagem de cenas), caráter de ensino/aprendizagem (encenador e atores jogam sem que haja alguém que só ensine, tampouco quem só aprende) e pesquisa científica (relacionando experimentação prática com estudos teóricos). Tais aspectos nortearão os próximos encaminhamentos da pesquisa.

Palavras-chave: Jogos de improvisação. Sala de ensaio. Formação de professores.

Abstract: In this research, I start from the belief that the formation of the artist-teacherresearcher happens in the act of artistic creation, having the rehearsal room as a space of play that aggregates relationships among theatrical doing, the subjects and the world. Integrating the thematic axis Theater Teacher Training, I aim to understand how the creative, pedagogical and scientific aspects act in the experiences with improvisation games in the rehearsal room. To do so, I take as the basis consolidated theories of improvisation from the scope of theater teaching: creation of scenes, fruition and reception, presented as systems adaptable to 
different teaching / learning contexts, proposed by Augusto Boal (2015) and Viola Spolin (2010); as well as the pedagogical look of Jean-Pierre Ryngaert (2009) on the variety of game inducers and favorable and unfavorable aspects in improvisation. Through the records of theatrical creation processes, the games studied were selected, transcribed and categorized as games of initiation, assembly and tuning of scenes. Currently, the research requires application of the games in a training workshop to understand how they operate in the formation of the artist-teacher-researcher. As a partial conclusion, I understand that the games studied cover three aspects: artistic creation (by directing the assembly of scenes), teaching / learning character (playwright and actors play without someone who only teaches, nor who only learns) and scientific research linking practical experimentation with theoretical studies). These aspects will guide the next steps of the research.

Keywords: Improvisation games. Rehearsal room. Teacher training.

\section{Introdução}

O teatro contemporâneo desafia todas as linguagens que compõem o espetáculo a dialogarem entre si, inserindo-as num jogo de criação simultânea e quebra de hierarquias. No cotidiano da sala de ensaios, aprender e ensinar são peças complementares e o jogo com ambas leva à criação artística, ao desenvolvimento sensível do sujeito, à formação do professor de teatro e aos caminhos para uma pesquisa científica em Arte. Como espaço de jogo, a sala de ensaios rompe as fronteiras que separam reflexão crítica da prática criativa, fazendo percebermo-nos experimentadores de formas sempre provisórias,

No desenvolvimento desta pesquisa dentro do Programa de Pós-Graduação em Artes Cênicas da Universidade Federal da Bahia - PPGAC/UFBA, tenho analisado práticas teatrais que conduzi, no período de 2012 a 2016, nas cidades de Crato e Juazeiro do Norte, Ceará, com atores e não atores da região do Cariri. O objetivo da pesquisa é compreender quais aspectos dos jogos de improvisação contribuem para formação do artista-professor-pesquisador.

\section{Caminhos Teórico/Metodológicos}

Inspirado por pesquisas consolidadas na área de jogos de improvisação teatral, três referenciais foram tomados como base para a primeira etapa, referente à análise das práticas: 1. Construção cênica por meio de jogos e inserção do espectador na cena, proposta por 
Augusto Boal, com intuitos educativos, sociais e políticos, evidenciando também a fruição e recepção como experiência criativa; 2. As contribuições de Viola Spolin, com práticas de improvisação e sistematização de jogos adaptáveis a diferentes contextos de ensino/aprendizagem; 3. O olhar pedagógico de Jean-Pierre Ryngaert, apontando diversos exemplos de indutores de jogo, descrições de atitudes a favor e obstáculos enfrentados pelos jogadores como princípios para compreender o movimento do jogo em curso.

Com as considerações acerca da funcionalidade e adaptabilidade dos jogos que apresentam em suas vastas bibliografias, os três teóricos supracitados me fazem olhar para os aspectos formativos das experiências que analiso. Através de suas metodologias, venho analisando práticas e levantando reflexões acerca da contribuição dos jogos de improvisação na formação do artista-professor-pesquisador.

Através de projetos de encenação, planos de ensaio e diários de bordo, os jogos foram selecionados e transcritos, apresentando o passo a passo, do tema inicial à montagem da cena. No percurso da pesquisa, foram categorizados como jogos de iniciação, montagem e afinação de cenas. O próximo passo da pesquisa é aplicar os jogos em oficina de formação com professores de teatro atuantes em espaços de ensino não formal (Centros Culturais e ONGs), que tenham, como parte dos seus processos pedagógicos, o exercício de montagem de espetáculos. Com isso, pretendo compreender a atuação do professor: sua condução, estado de jogo e reflexão crítica através do prática com jogos de improvisação.

\section{Considerações Atuais}

Revisitar os registros dos processos e analisar os jogos tem sido uma produção críticoreflexiva sobre minha condição de professor de teatro em constante formação, levando em conta as atividades que venho desenvolvendo ao longo dos últimos 6 anos no Cariri cearense.

Tenho identificado que os jogos de improvisação estudados apresentam 3 funções na formação do artista-professor-pesquisador de teatro. O primeiro é a criação artística, pois todos têm a cena como objetivo. O segundo é o caráter de ensino/aprendizagem, porque mesmo que o professor assuma a liderança, todos os jogadores estão desafiados pela improvisação, os riscos e descobertas são assumidos por todos. Terceiro, a característica de pesquisa científica, que agrega experimentação prática e estudos bibliográficos. Essas considerações acerca das característica dos jogos estão sendo fundamentais para a projeção da oficina, próxima fase da pesquisa. 


\section{Referências Bibliográficas}

BOAL, Augusto. Jogos para tores e não atores. São Paulo: Cosac Naify, 2015.

RYNGAERT, Jean-Pierre. Jogar, representar: práticas dramáticas e formação. São Paulo: Cosac Naify, 2009.

SPOLIN, Viola. Improvisação para o teatro. São Paulo: Perspectiva, 2010.

TELLES, Narciso. Paragens de um artista-docente-pesquisador. In: TELLES, Narciso (Org). Pesquisa em Artes Cênicas. RJ: e-papers, 2012. 